\title{
Injerto de Piel en Territorio Oral: Presentación de un Caso
}

\author{
Skin Graft in Oral Cavity. Case Report
}

\author{
Alarcón Arratia Ana'; Muñoz Repetto Maximiliano² \& Moreno Fluxá Begoña ${ }^{2,3}$
}

\begin{abstract}
ALARCÓN, A. A.; MUÑOZ, R. M. \& MORENO, F. B. Injerto de piel en territorio oral: Presentación de un caso. Int. J. Odontostomat., 12(4):401-406, 2018.

RESUMEN: Los injertos de piel consisten en la toma de un segmento de epidermis y dermis logrando una separación completa del sitio dador y del aporte vascular, transfiriéndolos a un sitio receptor. Existen dos tipos de injertos de piel: de espesor parcial y de espesor total. En cavidad oral se utilizan en reconstrucción de lengua, piso de boca, mucosa bucal y defectos producto de maxilectomías. Se presenta el caso de un paciente sexo masculino 26 años que acudió por secuela de tejidos duros y blandos secundarios a trauma facial hace 7 años. Al examen se observó pérdida de fondo de vestíbulo en sector mandibular anteroinferior y pérdida de piezas anteroinferiores. Bajo anestesia general, se realizó vestibuloplastía más injerto de piel de espesor parcial abordando el antebrazo izquierdo de donde se tomó el injerto de piel con el dermatomo. Se llevó el injerto a boca posicionándolo con la dermis hacia la zona cruenta del sitio receptor, cubriendo la cara interna de labio denudada y fijándolo con sutura continua. Se instaló splint de acrílico en el área para mantener colgajos en posición fijándolo con 3 tornillos de $15 \mathrm{~mm}$. Debemos considerar todos los requisitos funcionales de la cavidad oral al momento de planificar una reconstrucción. El injerto de piel de espesor parcial permite tener una buena resistencia, movilidad adecuada y menor contracción por cicatrización. El paciente evoluciona de manera satisfactoria con una clara mejoría en la función labial, en la morfología del vestíbulo oral y en su estética.
\end{abstract}

PALABRAS CLAVE: injerto de piel, vestibuloplastía.

\section{INTRODUCTION}

Las pérdidas dentarias junto a sus tejidos de soporte pueden resultar en un reborde alveolar atrófico, con o sin escasa encía adherida y con una profundidad de vestíbulo incompatible con la rehabilitación bucal ya sea mediante implantes o prótesis removible. Esta situación puede ser consecuencia de exodoncias por caries o enfermedad periodontal, sin embargo, el mayor desafío se encuentra en secuelas de grandes traumas o cirugías resectivas secundarias a neoplasias $\mathrm{u}$ otras lesiones de los maxilares que resultan en bridas cicatrizales importantes que comprometen, además de la masticación, a la fonación, deglución y estética del paciente, lo que finalmente puede limitarlo en el ámbito psicológico y social.

Para asegurar la rehabilitación de este tipo de pacientes es necesario planificar sobre los tejidos dis- ponibles, que involucran estructuras óseas y tejidos blandos con características particulares. Muchas veces nos encontraremos con reborde óseos insuficientes, que pueden ser solucionados mediante las distintas técnicas de injertos óseos; insuficiente encía adherida, casos a los que aplican técnicas de injertos de encía; y/o insuficiente profundidad de vestíbulo para las que ocupamos las técnicas de vestibuloplastía, zplastias o rotación de colgajos. Considerando la complejidad de los casos que se ven involucrados, para alcanzar los objetivos probablemente sea necesario llevar al paciente a pabellón en más de una oportunidad.

A continuación, se presenta un caso de vestibuloplastía con injerto de piel como alternativa viable para devolver la funcionalidad al labio inferior y

\footnotetext{
${ }^{1}$ Servicio de Cirugía Oral y Máxilofacial, Hospital Clínico San Borja Arriarán. Santiago de Chile. Departamento de Cirugía Oral y Máxilofacial. Facultad de Odontología de la Universidad de Chile.

${ }^{2}$ Cirujano Dentista, Práctica privada, Chile.

${ }^{3}$ Escuela de Pregrado, Facultad de Odontología de la Universidad de Chile.
} 
dicho sea de paso dar soporte en tejidos blandos previo a rehabilitación odontológica en un paciente con secuela de trauma facial.

Injertos de Piel. Los injertos de piel consisten en la toma de un segmento de epidermis y dermis logrando una separación completa del sitio dador y del aporte vascular, transfiriéndolos a un sitio receptor (Lau \& Younger, 2011). Son utilizados en variadas situaciones clínicas: desde pacientes quemados hasta la reconstrucción de defectos de tejidos blandos secundarios a traumatismos o cirugías resectivas.

Los mayores avances de esta técnica se han realizado en los últimos 200 años (Singh et al., 2017), donde injertos de espesores parciales de tejido, permiten obtener una cicatrización más rápida, menor tamaño de la cicatriz y menor contracción del tejido injertado. En la actualidad, los injertos de piel son un procedimiento utilizado en múltiples especialidades en todas las áreas del cuerpo (Singh et al.). de piel:

Según su grosor, existen dos tipos de injertos

- Injertos de piel de espesor total.

- $\quad$ Injertos de piel de espesor parcial, el cual contiene a la epidermis y distintos grosores de la dermis dependiendo del espesor deseado para realizar el injerto.

La selección de cada tipo de injerto de piel depende de las características de la herida, ubicación del sitio receptor, tamaño y grosor del defecto y consideraciones estéticas.
Las ventajas y desventajas se presentan en la Tabla I (Zender \& Petruzzelli, 2005; Le Cocq \& Stanley, 2011; Lau \& Younger).

En cavidad oral, los injertos de piel se pueden utilizar en una amplia variedad de escenarios siendo útiles en reconstrucción de lengua, piso de boca, mucosa bucal y defectos producto de maxilectomías, permitiendo preservar la movilidad de la lengua. Por lo general se utilizan injertos de piel de espesor parcial que se fijan mediante suturas al defecto en tratamiento, siendo esta fijación de vital importancia ya que permite prevenir el "sheering" y la pérdida del mismo. La principal utilidad de estos injertos es que permiten la preservación de la función masticatoria y fonación (Zender \& Petruzzelli). Usualmente los injertos de piel en cavidad oral son de espesor medio: 0,016 a 0,018 pulgadas por lo que se debe medir un adecuado grosor y ancho del injerto de piel (Le Cocq \& Stanley; Lau \& Younger). La técnica del injerto de piel no está exenta de complicaciones y existen múltiples razones por las que pueden fallar, dentro de las que se encuentran: infecciones debido a piógenos, preparación indebida del sitio receptor, hematoma y fijación inadecuada del injerto y desbridamiento si el injerto es expuesto a estrés mecánico (Zender \& Petruzzelli; Le Cocq \& Stanley).

Los requisitos para que el injerto se estabilice en el sitio receptor son (Zender \& Petruzzelli; Le Cocq \& Stanley).

Sitio receptor vascularizado.

Inmovilización del injerto.

Mínimo estrés físico en el sitio receptor.

Tabla I. Injerto piel espesor parcial frente a injerto piel espesor total. Medidas en pulgadas. *Pulg: pulgadas.

\begin{tabular}{|c|c|c|c|}
\hline & Características & Ventajas & Desventajas \\
\hline $\begin{array}{l}\text { Injerto piel } \\
\text { espesor parcial }\end{array}$ & $\begin{array}{l}\text { Epidermis más grado variable } \\
\text { de dermis, dividiéndose en: } \\
\text {-Fino: } 0,005-0,012 \text { pulg. } \\
\text {-Intermedio: 0,012 - } 0,018 \\
\text { pulg. } \\
\text {-Grueso: 0,018-0,030 pulg. } \\
\text { En general tienen buenos } \\
\text { resultados funcionales pero } \\
\text { estéticos menos favorables. }\end{array}$ & $\begin{array}{lr}\text { Respuesta } & \text { favorable } \\
\text { incluso en } & \text { situaciones } \\
\text { no ideales. } & \end{array}$ & $\begin{array}{l}\text { Al ser más delgados, tienen menor } \\
\text { respuesta frente a in fecciones y } \\
\text { trauma. Pueden resultar insuficientes } \\
\text { en reconstrucciones en donde hay gran } \\
\text { pérdida de volumen de tejido. Tienen } \\
\text { mayor tendencia a } \\
\text { hiper/hipopigmentarse. Peor resultado } \\
\text { estético (pigmentaciones, falta de } \\
\text { folículos pilosos, mayor contracción de } \\
\text { herida). }\end{array}$ \\
\hline $\begin{array}{l}\text { Injerto piel } \\
\text { espesor total. }\end{array}$ & $\begin{array}{l}\text { Epidermis más dermis } \\
\text { completa incluyendo todos los } \\
\text { elementos contenidos de la } \\
\text { dermis. }\end{array}$ & $\begin{array}{l}\text { Se mantienen la mayor } \\
\text { cantidad de } \\
\text { características de la } \\
\text { piel del sitio donante, } \\
\text { obteniendo mejor color } \\
\text { y textura. Menor } \\
\text { contracción del injerto. }\end{array}$ & $\begin{array}{l}\text { Limitación del tamaño del injerto, ya } \\
\text { que en el sitio dador se intenta cerrar } \\
\text { por primera intención (aunque puede } \\
\text { ser cubierto por un injerto de piel de } \\
\text { espesor parcial). Requiere mejores } \\
\text { condiciones del sitio receptor para } \\
\text { tener un resultado favorable. } \\
\text { Indicaciones más limitadas. }\end{array}$ \\
\hline
\end{tabular}


El injerto no se estabiliza si se aplican fuerzas que provoquen que se deslice en la superficie. Para contribuir a este proceso se deben considerar otros procedimientos, tales como la fijación del injerto con un splint acrílico por 14 días o la necesidad de realizar una traqueostomía para mantener la permeabilidad de la vía aérea, con el fin de disminuir las cargas sobre el nuevo tejido. Además, es importante controlar el desarrollo de hematoma bajo el injerto, ya que impide una correcta adhesión al sitio receptor. Se pueden realizar múltiples cortes en la superficie del injerto al momento de posicionarlo para evitar la acumulación de sangre y exudado celular (Zender \& Petruzzelli; Le Cocq \& Stanley; Lau \& Younger).

Es importante considerar los requisitos funcionales de la cavidad oral al momento de planificar una reconstrucción con injerto. Frente a ellos, el injerto de piel de espesor parcial permite tener una buena resistencia, junto con movilidad adecuada y menor contracción por cicatrización. Este tipo de injerto permite reconstruir gran variedad de sitios de la mucosa oral tales como piso de boca, trígono retromolar y glosectomía parcial o hemiglosectomía además de defectos de la mucosa oral.

\section{CASO CLÍNICO}

Acude a la unidad de cirugía maxilofacial del Hospital Clínico San Borja Arriarán derivado desde cirugía plástica, un paciente sexo masculino 26 años sistémicamente sano por secuela de trauma facial de 7 años de antigüedad. Al examen presentaba extensa cicatriz en región mentoniana que involucraba labio

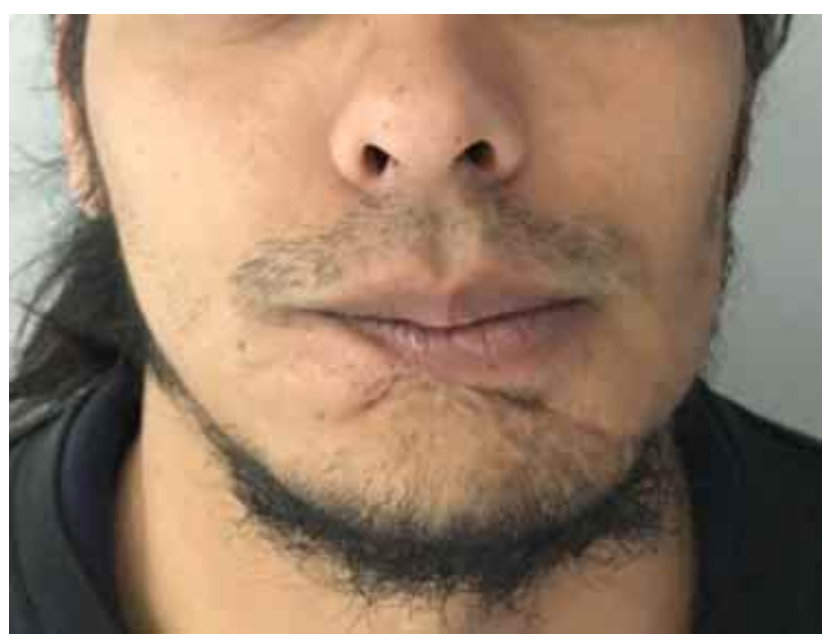

Fig. 1. Imagen extraoral preoperatoria. inferior y fondo de vestíbulo en sector mandibular anterior, con gran brida cicatrizal que impedía la correcta función, además de pérdida de los cuatro incisivos y caninos inferiores (Figs. 1 y 2 ).

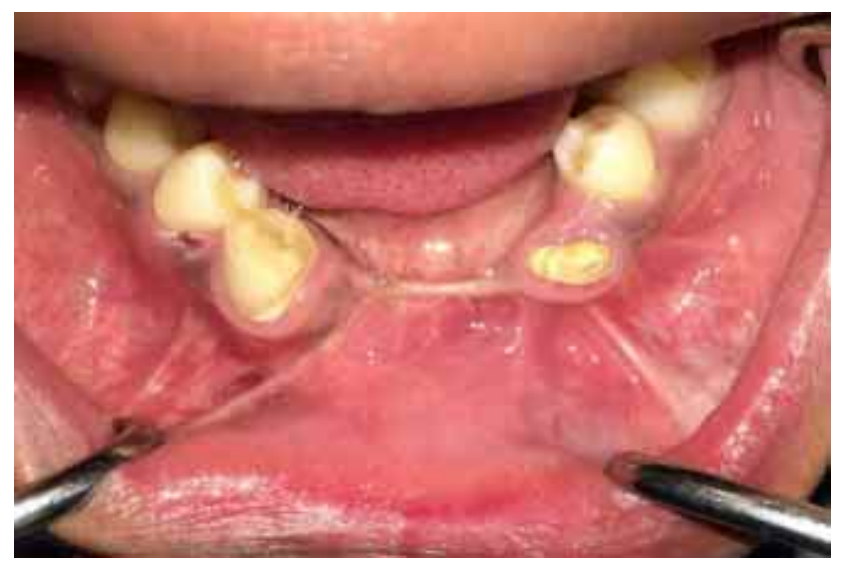

Fig. 2. Imagen intraoral preoperatoria.

Se planificó cirugía de vestibuloplastía más injerto de piel por la magnitud de la pérdida de tejidos blandos.

Para asegurar la estabilidad del colgajo mucoso y del injerto de piel en boca, se tomó una tomografía computada para confeccionar un modelo estereolitográfico de la mandíbula del paciente, sobre el cual se fabricó un splint acrílico de dimensiones definidas adaptándolo a la superficie mandibular.

Bajo anestesia general, se realizó preparación de dos campos quirúrgicos, uno para acceder al antebrazo izquierdo y otro en el área perioral. Se abordó el campo oral, infiltración anestésica mentoniana bilateral e incisión con bisturí frío en mucosa gingival hacia mucosa labial diseñando un colgajo mucoso en paleta, separando solo mucosa oral hasta alcanzar el reborde alveolar atrófico, el colgajo se sostiene temporalmente hacia intraoral con puntos suspensorios. Luego se abordó desde el reborde alveolar hacia caudal para realizar levantamiento de colgajo de espesor parcial (se deja periostio adherido a la superficie del hueso mandibular), la diéresis alcanza hasta $1 \mathrm{~cm}$ por sobre el margen basilar y en relación con el tamaño del splint acrílico previamente fabricado. Se logró soltar todas las bridas cicatrizales y se retiraron elementos de osteosíntesis instalados al momento de sufrir el trauma facial, considerando en que podrían interferir en la futura rehabilitación dentaria. Luego de esto, se reposicionó la paleta de mucosa anteriormente dejada hacia lingual, rotándola hacia caudal y suturándola con puntos suspensorios hacia la piel (Prolene 5.0) y 
sutura continua (Vicryl 4.0) de manera de dejar el colgajo mucoso en paleta completamente apoyado en el periostio (Fig. 3). Se cubrió el campo oral con paños estériles, se realizó cambio de guantes estériles y se abordó el campo del antebrazo izquierdo para la toma de injerto de piel. Se humecta con suero estéril y se tomó el injerto de piel de espesor parcial de $8 \times 3 \mathrm{~cm}$ de 0,012 pulgadas de espesor $(0,03 \mathrm{~mm})$ utilizando para ello un dermatomo de aire comprimido (Zimmer, Warsaw, IN). La forma de tomar el injerto de piel (previa anestesia local del área) incluye entrar con el dermatomo en piel con un ángulo de $45^{\circ}$ que luego se estabiliza a $30^{\circ}$ para ir avanzando el ayudante debe ir aplicando tensión constante sobre la piel del sitio dador, para terminar la toma del injerto de piel (corte final), el mango del dermatomo se posiciona paralelo a la piel, movimiento que permite el corte neto final (Fig. 4). Se realizó hemostasia del sitio dador con solución adrenalinada 1:200.000, se cubrió la herida con apósito Jelonet $₫$, gasa apósito y finalmente venda elástica. El injerto se mantuvo en suero teniendo presente cuál es la superficie epidérmica y cuál es la parte dérmica.

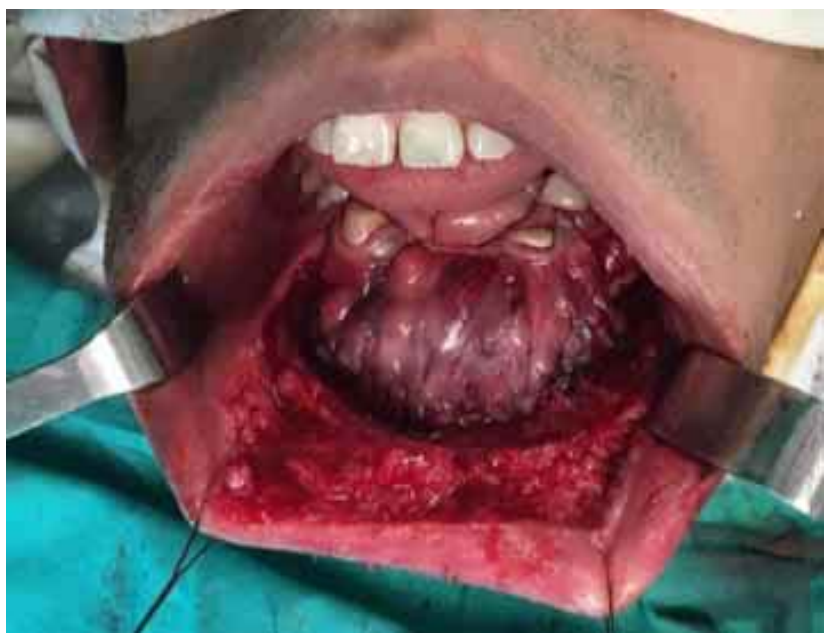

Fig. 3. Colgajo mucoso en paleta apoyado.

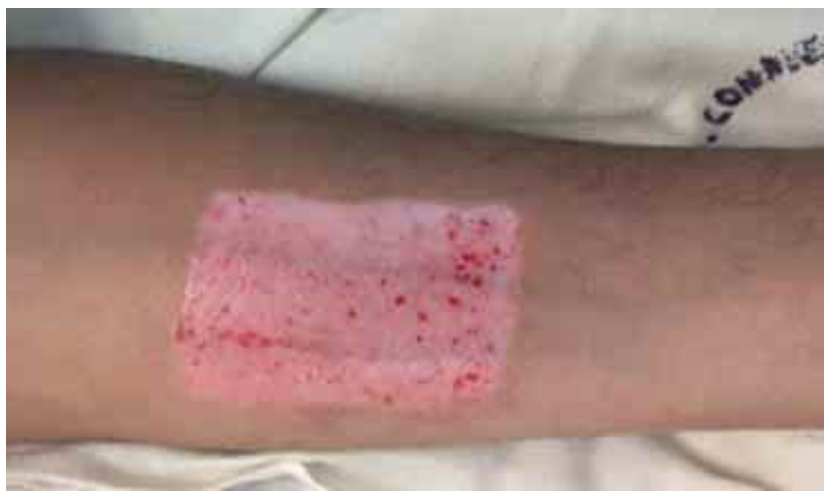

Fig. 4. Sitio dador injerto de piel en periostio con puntos suspensorios hacia la piel.
Se re abordó el campo oral y previa realización de pequeños cortes en la superficie del injerto de piel (para permitir el drenaje de exudado celular y de sangre) se lleva injerto al área que había quedado previamente descubierta al tomar el colgajo mucoso posicionándolo con la dermis hacia la zona cruenta del sitio receptor y fijándolo con sutura continua (Vicryl 6.0) (Fig. 5). Se instaló splint estéril en el área previamente definida para mantener el colgajo en posición fijándolo con 3 tornillos de $15 \mathrm{~mm}$ (Fig. 6). Se instaló venda adhesiva elástica (Microfoam®) sobre la piel del mentón de manera de mantener el injerto de piel adosado al splint que a su vez se encuentra sobre el colgajo mucoso.

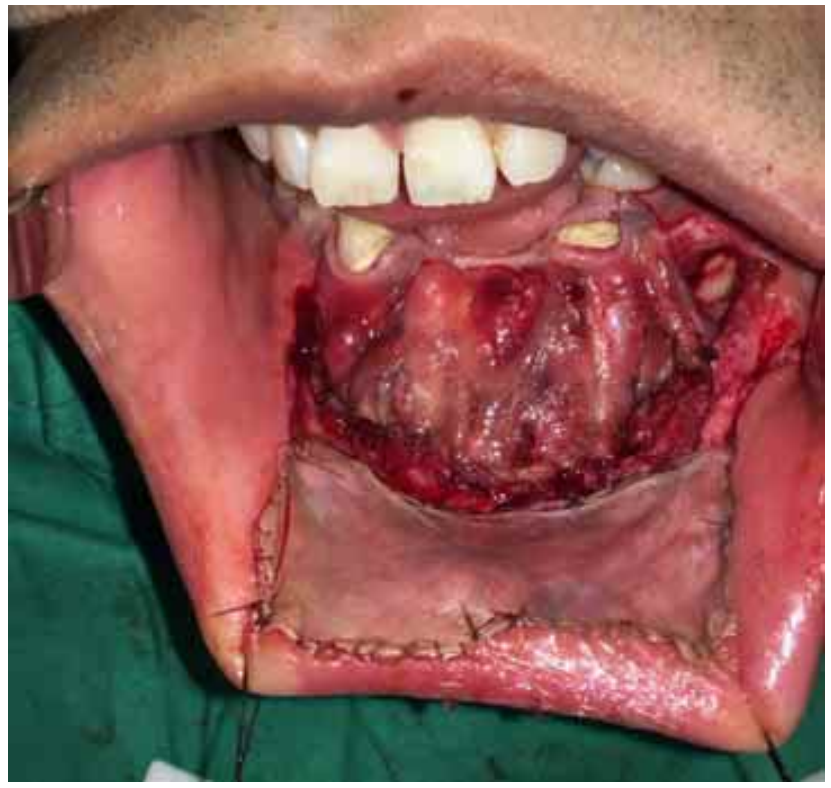

Fig. 5. Injerto de piel en posición.

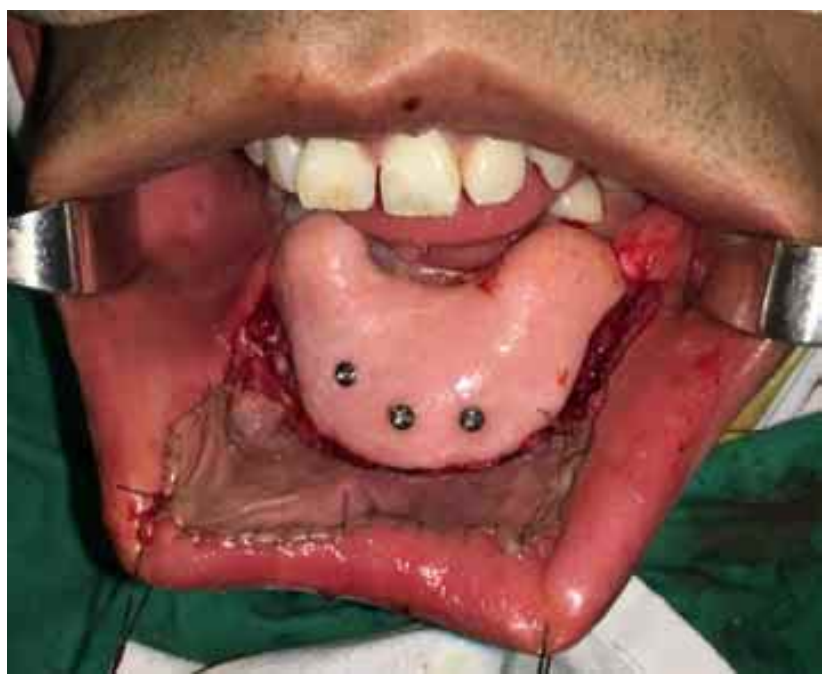

Fig. 6. Splint acrílico en posición. 
Posterior al procedimiento realizado, el paciente se mantuvo hospitalizado por 1 día. Se mantuvo dieta papilla completa por 14 días más higiene oral prolija y enjuague suave con clorhexidina.

Al septimo día se retiraron los puntos suspensorios cutáneos.

El splint acrílico se retiró al día 14 de postoperatorio, período durante el cual el injerto es más susceptible al estrés traumático y aún está desarrollando vascularización, además de ayudar a evitar la contracción por cicatrización manteniendo el contorno del surco vestibular.

En el antebrazo se retiró la venda y la gasa apósito solamente, el apósito Jelonet ${ }^{\circledR}$ excedente y ya suelto se recorta con una tijera estéril, el resto se mantuvo cubriendo el sitio dador del injerto en el antebrazo hasta que evoluciona el proceso de cicatrización y se produce la pérdida espontánea del mismo al día 12 de postoperatorio.

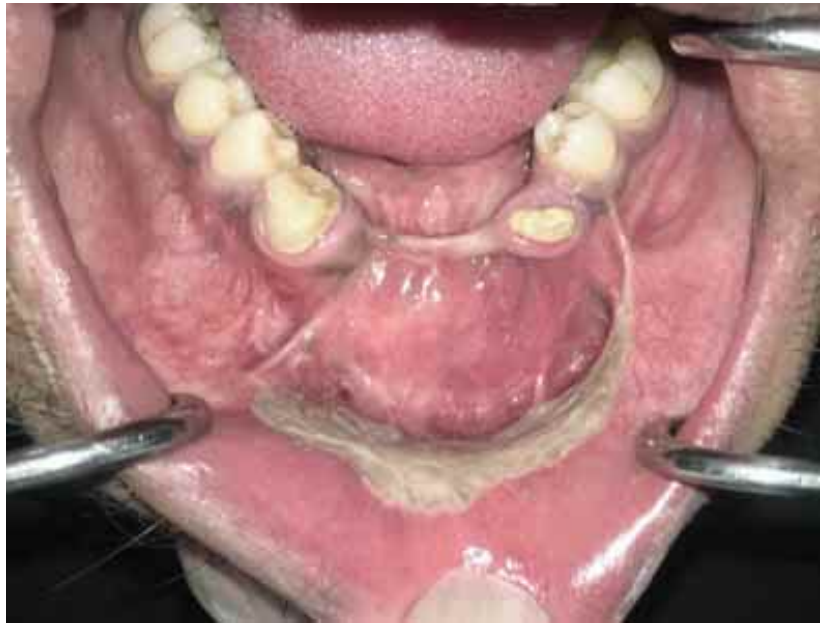

Fig. 7. Control a los 3 meses.

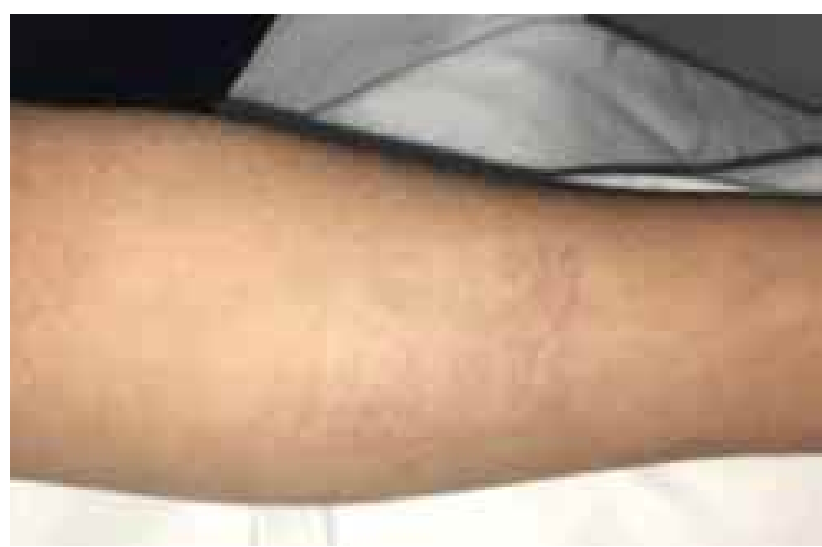

Fig. 8. Control a los 3 meses.
Se realizó la interconsulta a fisioterapia para manejo y prevención de cicatrices hipertróficas.

El paciente evoluciona con mejoría en su motilidad labial y morfología del vestíbulo oral, además el sitio dador cicatriza favorablemente (Figs. 7 y 8 ).

\section{DISCUSIÓN}

El enfoque de la intervención quirúrgica posterior a un trauma de gran envergadura debe considerar además de la funcionalidad, la rehabilitación que posteriormente se realizará, para lo cual es necesario considerar el estado de los tejidos duros y blandos del paciente. La fibrosis de la submucosa oral, pérdida de encía adherida y vestíbulo, más la reabsorción de la cresta alveolar secundaria a traumas dentoalveolares representan escenarios complejos que se pueden presentar al afrontar la rehabilitación del paciente (Kao et al., 2005).

Si bien, se podría pensar que la mayor dificultad para una rehabilitación se encuentra en relación al remanente de tejido duro ya que la cresta alveolar severamente atrófica suele presentar un contorno adelgazado con inserciones de frenillos y musculatura alta; el manejo de tejidos blandos es tan importante como el de tejidos duros al momento de planificar la rehabilitación (Kao et al.).

En relación al caso presentado, los tejidos blandos se encontraban francamente comprometidos lo que significaba una severa limitación de la funcionalidad del labio inferior, un vestíbulo bucal inexistente por la presencia de tejido cicatrizal y ausencia de encía adherida debido al trauma, lo que dificultaba enormemente la posterior rehabilitación ya sea con implantes o prótesis removible.

Es necesario tener una adecuada cantidad de encía adherida entorno a los implantes dentales para mejorar el pronóstico a largo plazo (Kao et al.; Esposito et al., 2012). En la literatura, existen dos ensayos clínicos aleatorizados que analizan las técnicas destinadas a manipular o aumentar los tejidos blandos ya sea por razones estéticas o reconstructivas para mejorar el pronóstico a largo plazo de la rehabilitación sobre implantes (Wiesner et al., 2010; Lorenzo et al., 2012). En un ensayo split-mouth, Wiesner et al. compararon el éxito y fracaso de implantes en tejidos donde fue aumentada la encía adherida con injerto conectivo frente a sitios donde no fue aumentada concluyendo que 
los injertos de tejido conectivo son efectivos para aumentar el espesor del tejido blando, mejorando así la estética y función de éstos.

Los injertos de piel de espesor parcial son ampliamente utilizados en el territorio oral debido su buena resistencia, movilidad adecuada y disponibilidad inmediata en su calidad de autoinjerto, además de poder cubrir grandes defectos (Kao et al.).

El manejo de los tejidos blandos con el injerto de piel de espesor parcial no logra resultados óptimos por sí solo, se debe realizar terapia kinesiológica ejercitando y reeducando la musculatura bucal, siendo esto tan importante como el procedimiento quirúrgico para obtener un buen pronóstico rehabilitador. El paciente debe tener controles periódicos debido a la tendencia que puede tener la mucosa a fibrosarse (Kao et al.).

En el caso expuesto, no se consideró necesario realizar un aumento de reborde alveolar óseo ya que el paciente presentaba tejidos duros suficientes para el proceso rehabilitador. Sin embargo, se debe evaluar el estado de los tejidos blandos y eventualmente considerar la posibilidad de realizar una segunda intervención con uso de encía queratinizada para aumentar encía adherida previo a la rehabilitación.

\section{CONCLUSIÓN}

Debemos considerar todos los requisitos funcionales de la cavidad oral al momento de planificar una reconstrucción. El injerto de piel de espesor parcial permite tener una buena resistencia, movilidad adecuada y menor contracción por cicatrización. El paciente evoluciona de manera satisfactoria con una clara mejoría en la función labial, en la morfología del vestíbulo oral y en su estética.

ALARCÓN, A. A.; MUÑOZ, R. M. \& MORENO, F. B. Skin graft in oral cavity. Case report. Int. J. Odontostomat., 12(4):401-406, 2018.

ABSTRACT: Skin grafts consist in taking a segment of dermis and epidermis, achieving a complete separation of the donor site and vascular supply, and transferring them to a receptor site. There are two types of skin grafts: split-thickness and full-thickness. In the oral cavity, they are used in tongue reconstruction, oral mucosa reconstruction, floor of mouth reconstruction and in defects product of maxillectomies. We present a case of a 26-year-old male patient who presented sequelae of hard and soft tissues secondary to facial trauma.
Clinical examination showed a compromised vestibule and loss of anterior mandibular teeth. Under general anesthesia, soft tissue management consisting of vestibuloplasty and a split-thickness skin graft was performed. The skin graft was taken from the forearm with a dermatome. The graft was then taken to the mouth with the dermis towards the wounded area of the recipient site, covering the inner face of the denuded lip and fixing it with sutures. An acrylic splint was installed in the area to keep the flaps and skin graft in position, fixing it with three $15 \mathrm{~mm}$ screws. We must consider all functional requirements of the oral cavity when planning a reconstruction. The split-thickness skin graft allows for good resistance, adequate mobility and less contraction due to scars. The patient evolves with definite improvement in labial function, the morphology of the oral vestibule and in its aesthetic.

KEY WORDS: skin graft, vestibuloplasty.

\section{REFERENCIAS BIBLIOGRÁFICAS}

Esposito, M.; Maghaireh, H.; Grusovin, M. G.; Ziounas, I. \& Worthington, H. V. Interventions for replacing missing teeth: management of soft tissues for dental implants. Cochrane Database Syst. Rev., 15(2):CD006697, 2012.

Kao, S. Y.; Lui, M. T.; Fong, J.; Wu, D. C.; Wu, C. H.; Tu, H. F.; Hung, K. F. \& Yeung, T. C. A method using vestibulo-sulcoplasty combining a split-thickness skin graft and a palatal keratinized mucosa graft for peri-implant tissue secondary to oral cancer surgery. J. Oral Implantol., 31(4):186-91, 2005.

Lau, B. \& Younger, R. A. L. Skin grafts in head and neck reconstruction. Oper. Tech. Otolaryngol., 22(1):24-9, 2011.

Le Cocq, H. \& Stanley, P. R. W. Closing the gap: skin grafts and flaps. Surgery, 29(10):502-6, 2011.

Lorenzo, R.; García, V.; Orsini, M.; Martin, C. \& Sanz, M. Clinical efficacy of a xenogeneic collagen matrix in augmenting keratinized mucosa around implants: a randomized controlled prospective clinical trial. Clin. Oral Implants Res., 23(3):316-24, 2012.

Singh, M.; Nuutila, K.; Collins, K. C. \& Huang, A. Evolution of skin grafting for treatment of burns: Reverdin pinch grafting to Tanner mesh grafting and beyond. Burns, 43(6):1149-54, 2017.

Wiesner, G.; Esposito, M.; Worthington, H. \& Schlee, M. Connective tissue grafts for thickening peri-implant tissues at implant placement. One-year results from an explanatory split-mouth randomised controlled clinical trial. Eur. J. Oral Implantol., 3(1):2735,2010

Zender, C. A. \& Petruzzelli, G. J. Skin grafting in oral cavity reconstruction. Oper. Tech. Otolaryngol., 16(1):24-7, 2005.

Dirección para correspondencia:

Ana Alarcón Arratia

Facultad de Odontología

Universidad de Chile.

Sergio Livingstone Pohlhammer 943

Independencia

Santiago

CHILE

Email: Anaalarcarr@gmail.com

Recibido : 12-06-2018

Aceptado: 08-10-2018 